\title{
Assessment of work ability of health professionals in the mobile emergency unit
}

\author{
Santos, $\mathrm{Y}^{1 *}$, Porto, $\mathrm{F}^{2}$, Marques, $\mathrm{L}^{1}$, Tomaz, $\mathrm{A}^{1}$, Toledo $\mathrm{R}^{2}$ and Lucena, $\mathrm{N}^{2}$ \\ ${ }^{1}$ UNIPÊ, University Center of João Pessoa, *Professor Artur Batista,635, Jaguaribe, João Pessoa, PB, Brazil, \\ 58015810,8388235804
}

${ }^{2} U F P B$, Federal University of Paraiba

\begin{abstract}
Ergonomics is the study of a workplace and the worker. Its aim is to better adapt the workplace to man by preserving the body for short and long term work. This helps to adjust and improve functionality, thus preserving the body for short and long term work. It was through the observation of SAMU's (Mobile Emergency Unit) professional's helpers that the interest to evaluate these individuals arose. In addition, the aim of this research is to investigate the work ability of health professionals that work for SAMU/JP. The population was composed of 97 health professionals who currently work for SAMU/JP. A sociodemographic questionnaire was used as data collection instrument and it was validated by the index of the Work Ability (WAI). The research took place in 2010, in the headquarters of SAMU, in the city of João Pessoa, state of Paraíba - Brazil. The data analysis was carried out by simple descriptive statistics followed by comparison of the results with the pertinent literature. The quantity of daily sleeping hours, the levels of satisfaction in the job and the number of diagnosed diseases were among the most worrying factors. In spite of this, the health professionals obtained a work ability average considered to be "good".
\end{abstract}

Keywords: health professionals, work ability, SAMU.

\section{Introduction}

In the mid of the XIX century working conditions were recognized as to be directly intertwined with the health of the professional on a daily basis. In the XX century, such knowledge progressed from medicine, public health and technological fields such as safety engineering and ergonomics, thus, incorporating the model for worker's health [11]. Ergonomics is in this context the study of work adaptation towards the worker, where the job itself is seen as wide figure, contemplating not only the environment and work materials but the organizational aspects, which may altogether have influence over the individual's work ability [5].

Work ability can be defined as how well one is or will be and how capable is such person of executing their job in light of their general health state as well as physical and mental health [7]. This same author affirms that work ability is the foundation for wellbeing in one's professional life and that it is not satisfactory unless work can be adapted to the worker. Seibt et al. [12] affirm that in order for the professional to obtain good work ability it is indispensable that he or she be in good health and satisfied with the job, aside from personal resources. Also, low physical and mental health are good examples for the decrease of work ability. The factors that can contribute to this decrease in ability are several and described in the following.

Among the factors with greater importance and incidence are: insalubrious work place, outsourcing, work intensification, increase in working hours, exposure to risk factors associated with the noncompliance to health safety rules, decrease in salary levels, low levels of work satisfaction, low resting time including sleeping hours and no leisure and physical activities. All of these influence directly the work ability [9].

It can be deduced from the strong relation between the ergonomic concepts with the work ability evaluation that the health professionals from

*Corresponding author. E-mail: yannobrega@hotmail.com

$1051-9815 / 12 / \$ 27.50$ C 2012 - IOS Press and the authors. All rights reserved 
the Mobile Emergency Unit (SAMU) are a classic example of what was mentioned. It was through the occasional observation of these rescuer professionals and of their work environment that arose the interest to evaluate the work ability of these individuals.

Since 1955 the fire squad has fulfilled the pre hospital service, which must be well structured in order to improve and qualify the services to urgencies, to decrease hospitalization time and to increase rehabilitation prognosis [15]. SAMU is one of the services provided by the Health System (SUS) comprising pre hospital service and the individuals who work in this service are known as professional rescuers. They work in mobile units of basic and advanced support, whose equipment are of easy transportation and maneuver in order to provide the most efficient service possible to someone in need in the most diverse places.

In the great majority of cases SAMU makes its way to the person that needs requested help through free telephone contact number 192 [8]. SAMU is responsible for reducing the number of deaths, hospitalization times and sequelae from the lack of early help. Currently, SAMU is present in all Brazilian states covering 1.502 cities. It is aimed to reach $100 \%$ cover by SAMU up to the end of 2014 $[15,9]$.

Given the above, the aim of this research is to investigate the work ability of health professionals who work with the Mobile Emergency Unit (SAMU/JP), using the Index of the Work Ability (WAI) as tool [14].

\section{Methodology}

This study is a result of a transversal field research with exploratory and descriptive character.

The population was composed of 97 health professionals (doctors, nurses, nursing technicians, pharmacists and pharmacy assistants), who currently work for SAMU/JP, however, only 52 took part in this study due to: 1) a lot of them being allocated to other strategic location in the city, in accordance with their work schedule; 2) refusal to answer the questionnaire and 3) having not been found on the pre established days for the data collection at the headquarters of SAMU/JP.

The data collection was only put forward upon authorization from the University's Ethical Committee, in accordance to the norms of
Resolution 196/96 which regulate research utilizing human beings.

The following were used as measuring instruments: a questionnaire to identify the sociodemographic profile of workers studied and index of the Work Ability (WAI), which is a selfadministered questionnaire that evaluates the physical and mental health for the job. The latter comprises of a total summed score ranging between 7 to 49 , whereby a score ranging from 7 to 27 is considered low; 28 to 36 is moderate; 37 to 43 is good and 44 to 49 is excellent. Also, it is composed of ten questions and it was validated, translated and adapted to Brazil by the index of the Work Ability (WAI), developed by the Occupational Institute of Finland, Helsinki, adapted to Brazil.

A sociodemographic questionnaire was used as data collection instrument and it was validated by the index of the Work Ability (WAI), developed by the Occupational Institute of Finland, Helsinki.

The data analysis was carried out by simple and descriptive statistics, using tables and graphics generated by the Microsoft Office Excel 2007 tools followed by comparison of the results against the pertinent literature.

\section{Results and discussion}

\subsection{Sample characterization}

The sample was constituted of 52 workers among the 96 health professionals employed at the headquarters of SAMU/JP. It was possible to observe that $60 \%$ (31) of the professionals are of the female gender and $40 \%$ (21) of the male gender, with a medium age of 36,07 years old and the minimum age was of 20 and the maximum of 56 . Studies with nurses from an university hospital's emergency room verified a correlation between age and early loss of work ability [2]. On the other hand, Fisher et al. [4] verified that nurses with more age (above 35 years old) showed greater work ability than the younger nurses. This study showed similar results to the latter, where professionals aging between 40-49 years old showed a better WAI than the younger ones, ranging between 20-29 years old.

As to the education level, it was seen that the majority of professionals showed completed higher education. None showed to have a masters or doctorate degree. 
It was observed that among the professionals who took part in the study 23 were nurse technicians, 16 were doctors, 9 were nurses and 4 were pharmacy assistants.

Such professionals have an average of 8,6 years of profession not taking into consideration only their work at SAMU/JP.

The working hours varied, thus being divided into monthly scales. The majority work from 6 to 12 hours a day and the minority work up to 6 hours. The remaining others showed to have working hours surpass the 12 hours per day.

The work satisfaction was reverberated in the following manner: very good, good, satisfactory and low. The majority showed a good satisfaction level [58\%] and nobody reported low levels. The greatest level of satisfaction came from among the pharmacy assistants and nurse technicians.

An item which deserves to be highlighted is the sleeping hours reported by the health professionals of SAMU/JP. According to Cronfli [1], the sleeping hour necessity is an individual characteristic but the ideal would be 7 to 8 hours per day for adults. The study corroborates with this research, where 42 professionals reported to have between 7 and 8 daily sleeping hours. However, it must be taken into consideration that 8 professionals reported to have between 1 and 5 daily sleeping hours. This is a worrying fact for Cronfli [1] shows that someone with over 19 hours awake on a roll has a decrease in the metabolism in the frontal region of the brain (responsible for the ability to plan and execute tasks) and the cerebellum (responsible for the motor coordination), all of which are very important for a rescuer of SAMU.

The accumulated effects for people who sleep only 4 to 5 hours a day lead to high drowsiness levels thus increasing the chances of work accidents occurring [3].

With respect to regular physical activity, 52\% (27) of the health professionals of SAMU/JP reported not to undergo any.

A study carried out with employees of a public transport company showed that $88 \%$ had a sedentary life style, which leads to a decrease in the result of work ability as stress can cause physical, cardiovascular, asthma and rheumatoid arthritis problems [10].

It is known that physical activity acts effectively in the maintenance and reestablishment of work ability by increasing oxygenation at cellular level, decreasing stress and improving self-esteem [13].
Also, extreme physical demand at work decreases the WAI. Such observation is done between health professionals of SAMU and that can be an aggravating factor for the work ability of these individuals.

Another case study with workers from an administrative area verified that where the type of work is predominantly mental, the greater part of the WAI results showed good or great work ability [6].

\subsection{Work ability index}

The final work ability index for the health professionals of SAMU/JP was considered "good" with an average of 37,6 between themselves, where the minimum was 29 and the maximum 44 .

With respect to career years it was verified that the professionals who showed 11 to 20 years of profession have a better work ability in comparison with the rest, obtaining a final score of $30-$ considered "good"; the lowest score was shown by the professionals with longer years on the profession (21-30 years), obtaining 36, 5- considered "moderate" for an ideal work ability.

The scores shown for ideal work ability for the working hours were homogeneous. The professional with daily working hours higher than 12 scored 37 , 75 and that is considered to be "good". The ones who work 6 to 12 hours a day showed the smallest score with 37,48 , which is also considered to be "good" for the current work ability.

As for the daily sleeping hours, the greatest WAI average result came from the workers who sleep between 9 and 12 hours, scoring 41, 5 - considered to be "good" - and the lowest was shown from the ones who sleep between 1 and 5 hours, scoring 36, 62 - considered to be "moderate". Such results can be explained by the fatigue and other negative symptoms previously explained brought about by the lack of sleep (Table 1).

The highest WAI result for level of satisfaction with the job was "good" with an average of 39, 56 and the lowest was attributed to the professionals that marked "regular" for level of satisfaction. The latter had an average of 35, 5 for the WAI index, which is considered to be a "moderate" average (Table 2).

When observing the work ability in relation to the physical demands the average found was of 39,37 , which is considered to be "good" and the lowest average was of 31,5 , which is considered to be "moderate". 
The diagnosed diseases reported by the professionals in this study comprise a worrying fact. Among the most frequent, the following were identified: 6 people reported to suffer from chronic rhinitis, 6 reported problems gastritis, 5 have some kind of lesion in their spine region, 5 have arterial hypertension, 4 suffer from disease or lesion related to their vision, 4 from urinary tract infections and 4 from allergy/eczema. With respect to the WAI, it was observed that the professionals suffering from 1 to 2 diseases obtained a result of 36,63 ("moderate") and the ones suffering from more than 5 diseases showed a result of 30,5 ("moderate") (Table 3).

The professionals with only 1 to 2 diseases obtained a better WAI average result than the ones with 3 or more, thus this variable being a relevant finding in the study.

Table 1

Results of the Work Ability Index with respect to daily sleeping hours.

\begin{tabular}{lll}
\hline Hours of sleep & Average WAI & Classification \\
\hline $1-5$ hours & 36,62 & Goderate \\
$6-8$ hours & 37,61 & Good \\
$9-12$ hours & 41,5 & Good \\
\hline
\end{tabular}

Table 2

Results of the work ability index for levels of satisfaction in the job.

\begin{tabular}{lll}
\hline Level of satisfaction & Average WAI & Classification \\
\hline Weak & - & - \\
Regular & 35,5 & Moderate \\
Good & 37 & Good \\
Very good & 39,56 & Good \\
\hline
\end{tabular}

Table 3

Results of the work ability index for work for the number of diseases.

\begin{tabular}{lll}
\hline Number of diseases & Average WAI & Classification \\
\hline $1-2$ & 36,63 & Moderate \\
$3-4$ & 34,16 & Moderate \\
$\geq \operatorname{than} 5$ & 30,5 & Moderate \\
\hline
\end{tabular}

\section{Conclusion}

We observed a final WAI average for all the professionals of 37,6 - considered to be "good". However it is valid to question and monitor for taking into consideration the work they conduct, the professionals of SAMU need higher attention, orientation and care, especially with respect to the sleeping hours, levels of work satisfaction, physical demand and the number of diseases shown. Such situations when not satisfactory can lead not only to risks to the professionals but also to those who 
receive their assistance. The results indicate the need for programs directed to the levels of health care and work satisfaction.

\section{References}

[1] Cronfli, R. T. A importância do Sono. Available at $<$ http://www.cerebromente.org.br/> Access in 17/10/2010.

[2] Duran, E. C. M. e Cocco M. I. M. Capacidade para o trabalho entre trabalhadores de enfermagem do pronto-socorro de um hospital universitário. Revista Latino-Americana de Enfermagem, 12(1):43-9. 2004.

[3] Fischer, F. M. et al., Percepção de sono: duração, qualidade e alerta em profissionais da área de enfermagem. Caderno de Saúde Pública, Rio de Janeiro, 18(5):1261-1269, set-out, 2002.

[4] Fischer, F. M. et al., A (in)capacidade para o trabalho em trabalhadores de enfermagem. Revista Brasileira de Medicina do Trabalho, Belo Horizonte - MG, Brazil, 2005.

[5] Iida, I. Ergonomia Projeto e Produção. São Paulo: Edgard Blucher, 2001.

[6] Martinez, M. C. Saúde e capacidade para o trabalho em trabalhadores de área administrativa. Departamento de Epidemiologia, São Paulo, SP, Brazil, 2006.

[7] Martinez, M. C. (2007). Capacidade para o trabalho: revisão de literatura. Available from <http://www.abrasco.org.br/> Access in: 17/03/2010.

[8] MINISTÉRIO DA SAÚDE (2011). Serviço de Atendimento Móvel de Urgência - SAMU. Available at: $<$ http://portal.saude.gov.br/>. Access in: 24/07/2011.

[9] Pinheiro, D. F. Doença Osteomuscular Relacionada Ao Trabalho: Fator De Interferência Na Qualidade De Vida Dos Trabalhadores Do Samu 192/JP. 2008, 63f. Monografia (Graduation in Physiotherapy) - Centro Universitário de João Pessoa - UNIPÊ.

[10] Sampaio, R. F. et al., Work ability and stress in a bus transportation company in Belo Horizonte, Brazil. Federal University of Minas Gerais, Brazil, 2009.

[11] Santana, V. S., Saúde do trabalhador no Brasil: pesquisa na pós-graduação. Universidade Federal da Bahia, Salvador, BA, Brazil, 2006

[12] Seibt, R. et al., Predictors of work ability in occupations with psychological stress. Institute and Clinic of Occupational and Social Medicine, Germany, 2009.

[13] Silva, L. G. et al., Capacidade para o trabalho entre trabalhadores de higiene e limpeza de um hospital universitário público. Revista Eletrônica de Enfermagem, 12(1):158-63 2010. Available from: http://www.fen.ufg.br/revista/v12/n1/v12n1a19.htm.

[14] Tuomi, Kaija, et Work Ability Index. Helsinki: Institute of Occupational Health, 1997.

[15] Vieira, C. M. S. A implantação do Projeto de atendimento Móvel de Urgência em Salvador/BA: panorama e desafios. Revista da Escola de Enfermagem da USP, São Paulo, 42(4):793-7, 2008. 